УДК 669.017

\title{
Manipulation of Silumin Microstructure \\ in Liquid-Solid Condition, Using the Heat Treatment
}

\author{
Aleksey I. Anikin*, Sergey V. Belyaev, \\ Vladimir P. Zhereb and Valentina I. Anikina \\ Siberian Federal University \\ 79 Svobodny, Krasnoyarsk, 660041, Russia
}

Received 30.03.2015, received in revised form 21.05.2015, accepted 12.07.2015

In this paper we examine the effect of heat treatment on the structure of the eutectic aluminum alloys, a theoretical study process on the basis of the microstructures. The phenomenon of clustering of liquid metal solutions and develop in following this process, heterogenization solid phases in chemical composition.

Keywords: silumin, Al-Si, eutectic, heterogenization, dendrites, microstructure.

DOI: 10.17516/1999-494X-2015-8-5-582-593.

\section{Управление микроструктурой силуминов \\ термической обработкой \\ в твердо-жидком состоянии}

\author{
А.И. Аникин, С.В. Беляев, \\ В.П. Жереб, В.И. Аникина \\ Сибирский федеральный университет \\ Россия, 660041, Красноярск, пр. Свободныий, 79
}

В статье рассмотрено влияние режимов термической обработки на структуру эвтектических алюминиевых сплавов, проведено теоретическое обоснование процесса на основе полученных микроструктур. Изучено явление кластеризации жидких металлических растворов и развивающаяся вслед за этим процессом гетерогенизация твердых фаз по химическому составу.

Ключевые слова: силумин, Al-Si, эвтектика, гетерогенизация, дендрить, микроструктура.

(C) Siberian Federal University. All rights reserved

* Corresponding author E-mail address: anikin24081989@mail.ru 


\section{Введение}

В статье рассмотрено явление кластеризации жидких металлических растворов и развивающаяся вслед за этим процессом гетерогенизация твердых фаз по химическому составу. Использование этого явления позволяет разделить процесс кристаллизации жидких растворов на два этапа: диффузионное разделение и непосредственно кристаллизация гетерогенных кластеров.

Эвтектические алюминиево-кремниевые сплавы широко используются в автомобильной и авиационной промышленности благодаря своей низкой плотности и низкому коэффициенту теплового расширения. В зависимости от химического состава при традиционном способе кристаллизации алюминиево-кремниевого сплава могут образоваться как иглообразные кристаллы кремния, так и крупные первичные кристаллы кремния и эвтектические аккумуляторные плиты, что проводит к резкому увеличению хрупкости сплавов. Следовательно, возникают сложности, если требуется улучшить микроструктуру после литья.

Двойные металлические расплавы, или двойные жидкие растворы металов, - это макроскопические однородные конденсированные фазы, характеризующиеся атомным диспергированием компонентов и ближним порядком в расположении атомов. В подавляющем большинстве двойных металлических систем компоненты проявляют неограниченную взаимную растворимость в жидком состоянии. Если такая же растворимость наблюдается и в кристаллическом состоянии, т.е. существует непрерывный ряд твердых растворов от чистого компонента А до чистого компонента Б, то затвердевание расплава представляет собой однофазную кристаллизацию: жидкий АБ-раствор любой концентрации переходит в $\alpha$-твердый раствор.

Часто растворимость компонентов в кристаллическом состоянии ограничена, и если концентрация расплава превышает предел растворимости, то его затвердевание осуществляется путем многофазной кристаллизации. Одним из распространенных типов такой кристаллизации является эвтектическое превращение: диффузионное разделение расплава на две, кристаллические фазы образующиеся при одной температуре.

Необходимой предпосылкой эвтектического превращения служит, таким образом, отсутствие полной растворимости компонентов в кристаллическом состоянии.

\section{Эвтектика и дендритные структуры сплавов}

В эвтектических сплавах уже в жидком состоянии имеются области, обладающие структурой чистых компонентов, т.е. вблизи эвтектической точки можно проводить аналогию между структурой жидких и твердых эвтектических сплавов [1].

Смешение жидких компонентов - энергетически невыгодный процесс, который поэтому и не идет до конца. Расплавившиеся кристаллики компонентов эвтектики при температуре, немного превышающей температуру плавления, сохраняют до некоторой степени свою индивидуальность [2].

Таким образом, в подавляющем большинстве случаев дендритная кристаллизация сопровождается образованием эвтектических включений между ветвями дендритов. Можно даже сказать, что при полном затвердевании сплава дендритная кристаллизация почти всегда заканчивается кристаллизацией эвтектики [3].

$$
-583-
$$




\section{Кристаллизация эвтектики}

Рассмотрим вопрос о кинетике кристаллизации бинарных сплавов эвтектического типа.

При анализе эвтектического структурообразования прежде всего используют диаграммы состояния. Это не всегда делается корректно в том отношении, что линии термодинамического равновесия фаз принимают за линии начала или окончания кристаллизации. Описание кристаллизации с помощью равновесной фазовой диаграммы должно предусматривать возникновение температурно-концентрационных условий, являющихся отклонением от равновесных и нарушающих равенство химических потенциалов компонентов в фазах, что стимулирует фазовый переход. Эти отклонения связаны:

- с торможением диффузионного перераспределения компонентов между фазами и в фазах, заключающихся в образовании неоднородных твердых растворов;

- с появлением эвтектической структурной составляющей в сплавах, в которых еще не достигнут предел растворимости;

- с увеличением доли эвтектики против рассчитываемой для данного сплава по диаграмме состояния.

В морфологическом плане важно то, что в процессе диффузионного распада жидкости кристаллы эвтектических фаз могут зарождаться и расти порознь или совместно [4].

Изменение характера кристаллизации - переход от равноосной, хорошо ограненной формы роста к игольчатой - можно объяснить влиянием присутствия хотя бы и очень малочисленных, но всегда существующих примесей. Всякий кристаллик начинает расти в хорошо ограненной форме, но по мере роста вокруг него скапливаются оттесняемые на периферию инородные атомы и молекулы, которые в конце концов должны были бы создать пленку другого вещества, мешающего нормальному росту кристалла. Диффузия и конвекция не дают образоваться сплошному слою примесей и позволяют кристаллу расти. Однако при низких температурах, особенно при повышенном содержании примесей, влияние диффузии и конвекции недостаточно, чтобы обеспечить правильное питание кристалла по всем направлениям. При этом рост кристалла по нормалям к его граням затрудняется сильнее, чем тангенциальный рост граней путем перемещения ребер. Это объясняется большей омываемостью кристалла на ребрах, чем в центрах граней. Наибольшую скорость роста можно наблюдать там, где сильнее всего омывание кристалла жидкостью, т.е. по ребрам, и притом по ребрам меньших линейных размеров [3].

Следовательно, можно сделать вывод, что обычно наблюдаемые эвтектические структуры представляют собой частный случай дендритных структур.

Диаграмма состояния $\mathrm{Al}-\mathrm{Si}$ (рис. 1) разработана давно, исследования последних лет касаются главным образом уточнения растворимости кремния в твердом алюминии.

Диаграмма состояния Al-Si относится к эвтектическому типу. Эвтектика образуется между алюминием и кремнием при температуре $577{ }^{\circ} \mathrm{C}$ и концентрации кремния $12,2 \%$. Максимальная растворимость кремния при эвтектической температуре составляет 1,65 \%. По мнению Хансена и Андерко, наиболее точная растворимость кремния в алюминии получена в работе Дикса и Хиса, так как при исследовании был использован алюминий высокой чистоты и время отжига было достаточным для достижения равновесия. Растворимость кремния в алюминии, по их данным, следующая: 


$\begin{array}{lllllllll}\text { Температура, }{ }^{\circ} \mathrm{C} & 577 & 550 & 500 & 450 & 400 & 350 & 300 & 200 . \\ \text { Растворимость, } \% & 1,65 & 1,30 & 0,80 & 0,48 & 0,29 & 0,17 & 0,10 & 0,05 .\end{array}$

Близкие данные по растворимости кремния в алюминии получила М.И. Захарова.

Некоторые уточнения температуры и состава эвтектики алюминия с кремнием приведены в работе Эллиота:

- эвтектическая температура составляет $577,2{ }^{\circ} \mathrm{C}$, эвтектическая концентрация кремния $12,7 \%$;

- растворение кремния в алюминии уменьшает параметр решетки алюминия, каждый процент кремния уменьшает ее на $0,0017 \%$;

- сплавы Al-Si не упрочняются после термической обработки;

- сплавы Al-Si характеризуются хорошими литейными свойствами: высокой жидкотекучестью, хорошей герметичностью, а также высокой коррозионной стойкостью.

Значительным преимуществом алюминиевых сплавов с кремнием является сравнительно низкий коэффициент линейного расширения, благодаря чему эти сплавы нашли широкое применение для деталей точных приборов.

Влияние способа литья на уровень свойств определяется главным образом скоростью кристаллизации и функционально связанной с ней дисперсностью микроструктуры. При литье в песчаные формы и по выплавляемым моделям отливки охлаждаются и кристаллизуются медленнее, чем при литье в кокиль и под давлением. В результате дендритные ячейки (Al) и кристаллы избыточных фаз в отливках, закристаллизованные в металлических формах, оказываются заметно больше разветвленными, чем кристаллы кремния и других фаз в составе эвтектических колоний.

При старении после литья количество и морфология фаз кристаллизационного происхождения изменяются слабо. Происходит снятие литейных напряжений и распад алюминиевого

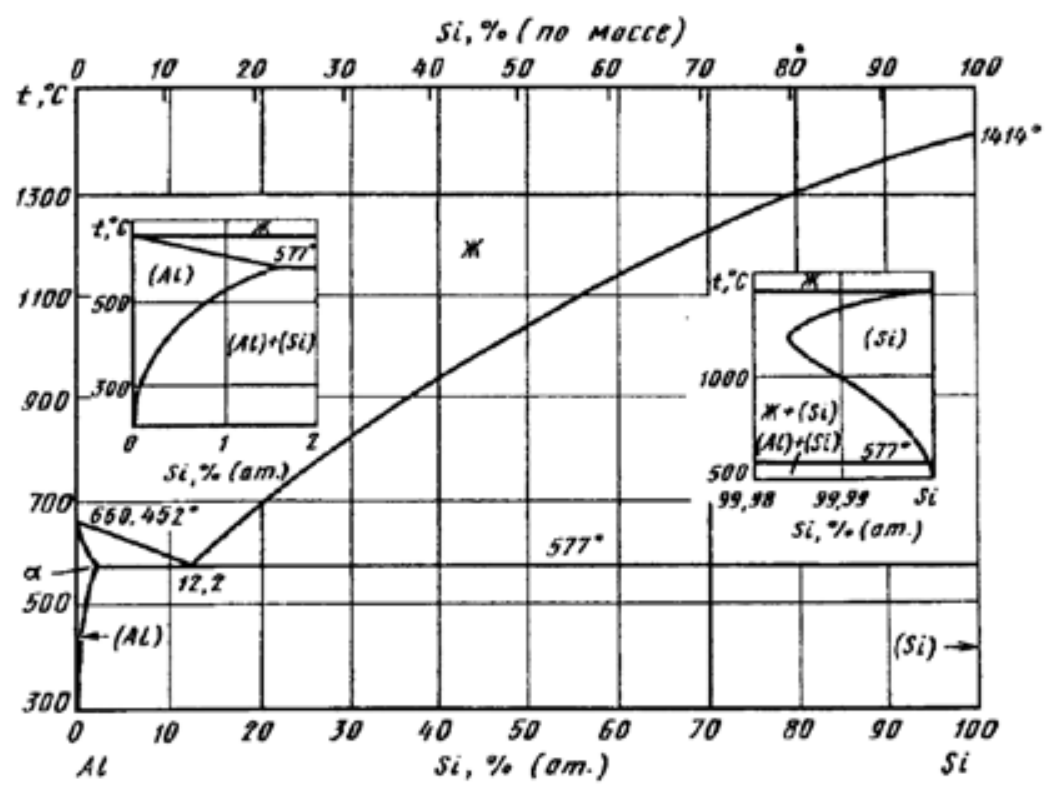

Рис. 1. Диаграмма состояния $\mathrm{Al}-\mathrm{Si}$ 
твердого раствора в тех микрообъемах, которые пересыщены в результате неравновесной кристаллизации относительно предельной растворимости при температуре старения [5].

Типичная микроструктура силумина состоит из мягкой пластичной фазы - $\alpha$-твердого раствора кремния в алюминии и эвтектики $\alpha+\mathrm{Si}$, состоящей из $\alpha$-твердого раствора и иголок кремния.

Двойные сплавы не упрочняются термической обработкой. Это объясняется высокой скоростью распада твердого раствора, который частично происходит уже при закалке, а также большой склонностью к коагуляции стабильных выделений кремния [6].

В качестве исходной заготовки для всех исследованных образцов использованы специально отлитые слитки.

Все образцы в исходном литом состоянии имели типичную структуру немодифицированного алюминий-кремниевого сплава (рис. 2).

В структуре видна типично игольчатая эвтектика (Al-Si) и избыточные дендритные кристаллы алюминиевого твердого раствора, что характерно как для доэвтектического сплава, так и для эвтектического, закристаллизованного в условиях существенного охлаждения (литье в металлическую форму).

Закалочный эксперимент предусматривал изучение характера изменения гетерогенного строения слабоперегретого расплава над точкой эвтектики в течение длительного времени - 10 ч - при температуре $580{ }^{\circ} \mathrm{C}$, т.е. на $3{ }^{\circ} \mathrm{C}$ выше температуры эвтектического равновесия $\left(577^{\circ} \mathrm{C}\right)$. Немедленное очень быстрое охлаждение в холодной воде, предотвращая диффузионное перераспределение компонентов за тысячные доли секунды (скорость охлаждения $\sim 10^{4}{ }^{\circ} \mathrm{C} / \mathrm{c}$ ), сохраняет в закаленном образце степень гетерогенности раствора, возникшего при нагреве и длительном выдерживании. Структура закаленного образца (рис. 3) отражает неоднородное распределение компонентов в таком растворе.

Следовательно, в жидком растворе в результате гетерогенизации возникают кластеры, обогащенные алюминием (светлые округлые дендриты), а также кластерные участки, обогащенные кремнием (области на фотографии, занятые высокодисперсной смесью темных и светлых кристаллов, располагающихся между кластерами, обогащенными алюминием). Такой характер структуры закаленного образца является важным свидетельством того, что области

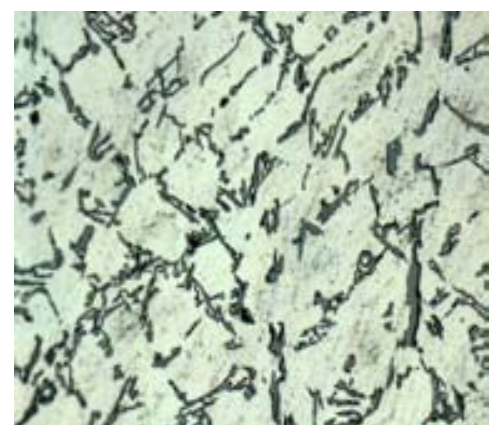

Рис. 2. Микроструктура сплава АК12 (исходное литое состояние)

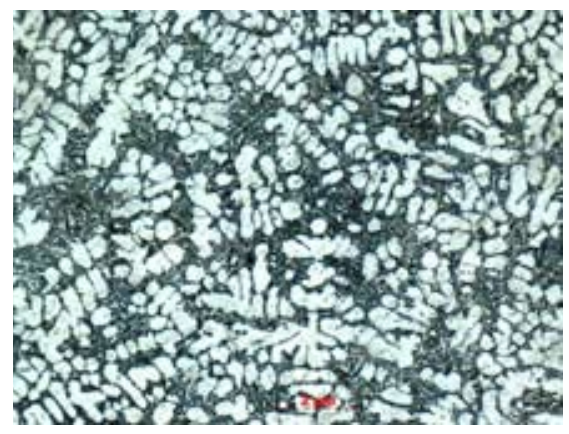

Рис. 3. Микроструктура сплава АК12 в закаленном состоянии $\left(\mathrm{T}_{3}=580{ }^{\circ} \mathrm{C}, \tau=10\right.$ ч, охлаждение в воде) 
в жидком растворе, обогащенном кремнием, не становятся сплошными кремниевыми кристаллами при сколь угодно длительной выдержке в субкристаллическом интервале температур выше точки эвтектического равновесия.

Поэтому все структуры, которые будут представлены, для различных условий длительности выдержки и охлаждения являются лишь отражением преобразования разнородных и однородных кластеров и взаимодействия при преобразовании их для формирования зародышей кристаллизации и роста кристаллов соответствующих фаз.

Конечная форма образующихся кристаллов зависит как от степени гомогенизации и гетерогенизации образующегося эвтектического расплава над точкой эвтектики в начальные периоды выдержки при температурах слабого перегрева, так и от условий взаимодействия сформированных кластеров между собой при последующем охлаждении с разной скоростью, определяя рост кристаллов различной формы и размеров (от мелких ориентированных, разориентированных компактных до крупноигольчатых и крупных компактных кристаллов).

Использование минимальной степени перегрева над точкой эвтектического равновесия (температура под закалку $\left(\mathrm{T}_{3}\right)$ составляет $0,580{ }^{\circ} \mathrm{C}$, т.е. на $3{ }^{\circ} \mathrm{C}$ выше $577{ }^{\circ} \mathrm{C}$ ), а также кратковременной выдержки (5 мин), обеспечивая переход в новое агрегатное состояние исходного образца и формирование его кластерного строения, не позволяет еще реализоваться каким-либо изменениям в форме и распределении областей в расплаве, обогащенных тем или иным компонентом, возникших при плавлении в микрообъемах, обогащенных алюминием и кремнием.

Поэтому характер распределения компонентов в расплаве повторяет картину их расположения в фазах исходного образца, из которого этот расплав образовался при перегреве.

Относительно быстрое охлаждение (на воздухе) такого расплава приводит к формированию структуры, напоминающей исходную структуру образца до расплавления.

Из кластеров, обогащенных алюминием, вновь формируются овальные зерна твердого раствора на его основе. Из кластеров, обогащенных кремнием, вновь формируются кремниевые кристаллы, располагающиеся в структуре в виде ориентированных игольчатых образований, наследующих свою форму также от исходной структуры первичного образца (рис. 4).

Увеличение степени перегрева на $8{ }^{\circ} \mathrm{C}\left(585^{\circ} \mathrm{C}\right)$ с той же длительностью выдержки в состоянии кластеризации (5 мин) приводит к более коренным преобразованиям в кластерной структуре только что полученного расплава.

Более высокая температура выдержки позволяет реализоваться частичному выравниванию кластерного строения за счет выравнивающей диффузии в жидкости и перераспределения кластеров между объемами, обогащенными алюминием и кремнием.

При охлаждении на воздухе более однородное кластерное строение расплава обеспечивает получение структур, слабо напоминающих исходное строение эвтектического сплава с более однородным распределением мелких кремниевых кристаллов, окруженных твердым раствором на базе алюминия (рис. 5).

Увеличение длительности выдержки кластеризованного сплава до 10 мин независимо от степени перегрева над точкой эвтектического равновесия $\left(3\right.$ и $8^{\circ} \mathrm{C}$, т.е. при температуре 580 и $585{ }^{\circ} \mathrm{C}$ ) приводит к усилению взаимодействия между кластерами, обогащенными кремнием, что, в свою очередь, приводит к образованию в структуре при охлаждении на воздухе компактных кремниевых кристаллов микронного размера, почти полностью свободных от грубых

$$
-587-
$$




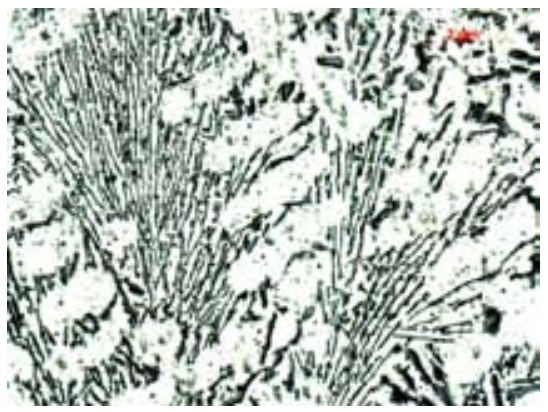

Рис. 4. Микроструктура сплава АК12 в термообработаном состоянии $\left(\mathrm{T}_{3}=580{ }^{\circ} \mathrm{C}\right.$, $\tau=5$ мин, охлаждение на воздухе)

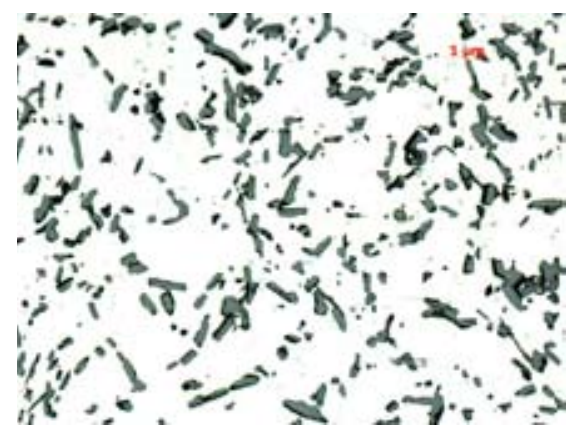

Рис. 6. Микроструктура сплава АК12 в термообработанном состоянии $\left(\mathrm{T}_{3}=580{ }^{\circ} \mathrm{C}\right.$, $\tau=10$ мин, охлаждение на воздухе)

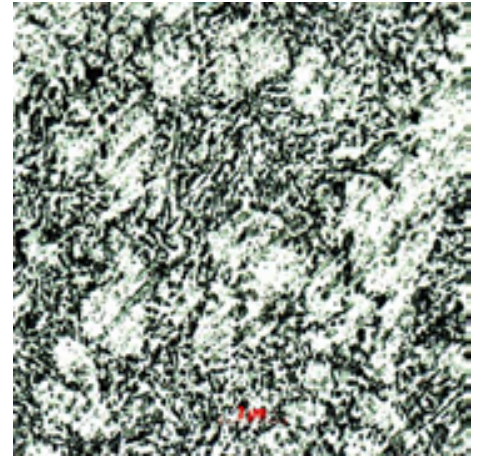

Рис. 5. Микроструктура сплава АК12 в термообработанном состоянии $\left(\mathrm{T}_{3}=585{ }^{\circ} \mathrm{C}\right.$, $\tau=5$ мин, охлаждение на воздухе)

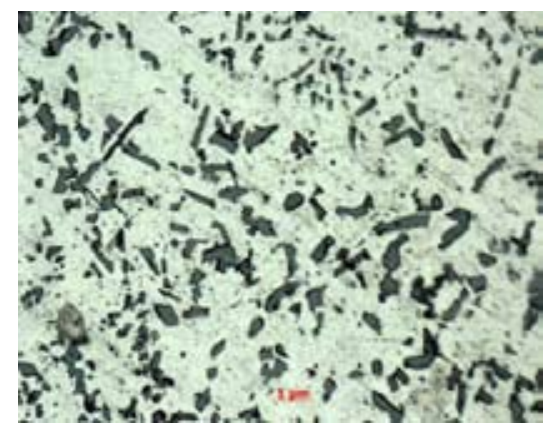

Рис. 7. Микроструктура сплава АК12 в термообработанном состоянии (Тз $=585{ }^{\circ} \mathrm{C}$, $\tau=10$ мин, охлаждение на воздухе)

игольчатых кремниевых выделений, окруженных матрицей из пластичного твердого раствора на основе алюминия (рис. 6 - 7), все микроструктуры получены при увеличении х500.

Дальнейшее увеличение времени выдержки в условиях кластеризации до 15 мин не позволяет сохранить компактную форму при последующей кристаллизации с охлаждением на воздухе (рис. 8 - 9).

Наряду с сохранением некоторого числа компактных кристаллов в структуре наблюдается преимущественно игольчатая пластинчатая форма кристаллов кремния. Этому способствуют процессы самоорганизации в кластерной структуре расплава, которые происходят за счет стремления системы к минимуму свободной энергии, когда на уровне наноразмерных кластеров они ориентируются в жидкости относительно друг друга одноименными кристаллографическими плоскостями. Большие скорости охлаждения (охлаждение на воздухе) способствуют реализации только одного из семейства кристаллографических направлений, что приводит к образованию пластинчатых (игольчатых на выявленных структурах) кристаллов.

Аналогичная форма кристаллов появляется при выдержке 15 мин (рис. 8) и при всех остальных исследованных, вплоть до 10 ч (рис. 10 - 13).

Причем эта закономерность сохраняется при температуре кластеризации как $580^{\circ} \mathrm{C}$, так и $585^{\circ} \mathrm{C}$ (рис. $14-16$ ), увеличение $\mathrm{x} 500$. 


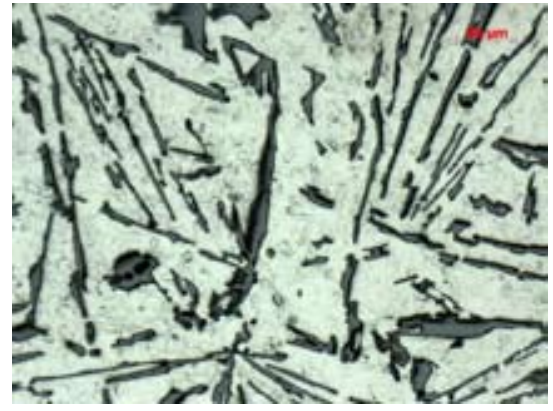

Рис. 8. Микроструктура сплава АК12 термообработанном состоянии $\left(\mathrm{T}_{3}=580{ }^{\circ} \mathrm{C}\right.$, $\tau=15$ мин, охлаждение на воздухе)

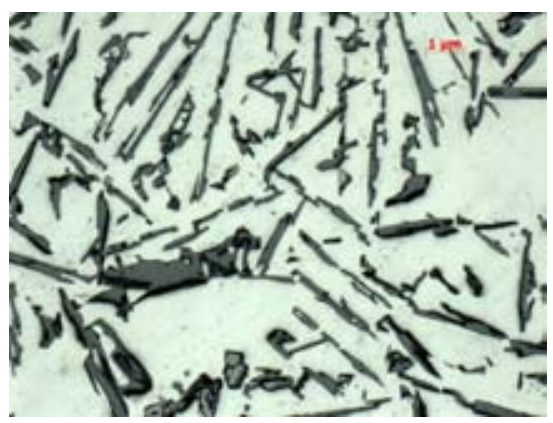

Рис. 10. Микроструктура сплава АК12 в термообработанном состоянии $\left(\mathrm{T}_{3}=580{ }^{\circ} \mathrm{C}\right.$, $\tau=20$ мин, охлаждение на воздухе)

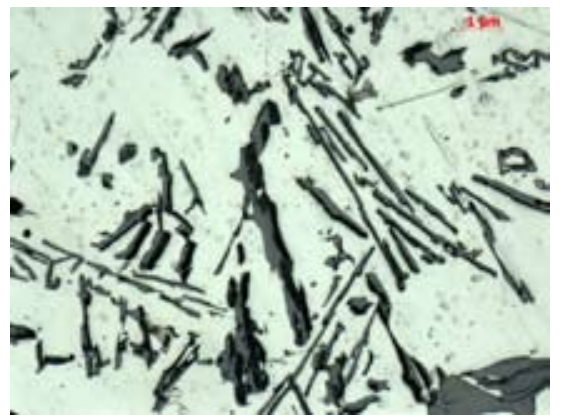

Рис. 12. Микроструктура сплава АК12 в термообработанном состоянии $\left(\mathrm{T}_{3}=580{ }^{\circ} \mathrm{C}\right.$, $\tau=60$ мин, охлаждение на воздухе)

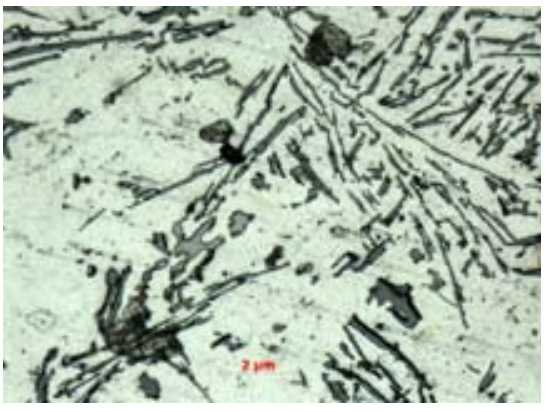

Рис. 9. Микроструктура сплава АК12 в термообработанном состоянии $\left(\mathrm{T}_{3}=585{ }^{\circ} \mathrm{C}\right.$, $\tau=15$ мин, охлаждение на воздухе)

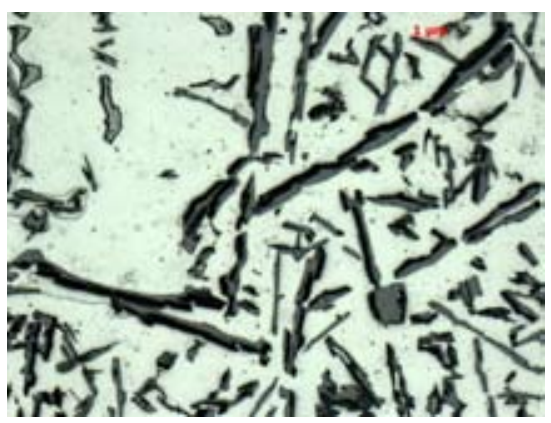

Рис. 11. Микроструктура сплава АК12 в термообработанном состоянии $\left(\mathrm{T}_{3}=580{ }^{\circ} \mathrm{C}\right.$, $\tau=30$ мин, охлаждение на воздухе)

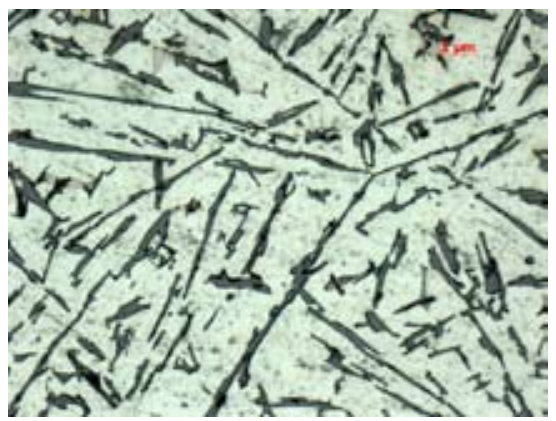

Рис. 13. Микроструктура сплава АК12 в термообработанном состоянии $\left(\mathrm{T}_{3}=580^{\circ} \mathrm{C}, \tau=10\right.$ ч, охлаждение на воздухе)

Формирование окончательной структуры сплавов, прошедших стадию разделительной кластеризации в расплаве выше точки эвтектического равновесия, определяется не длительностью выдержки, а скоростью охлаждения кластеризованного расплава в интервале изменения агрегатного состояния сплава. Поэтому было получено влияние способа охлаждения (в воде, на воздухе и с печью - в интервале кристаллизации) на структуру сплава АК12. 


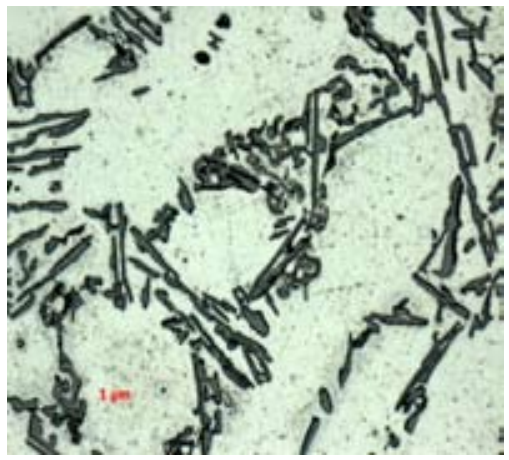

Рис. 14. Микроструктура сплава АК12 в термообработанном состоянии $\left(\mathrm{T}_{3}=585{ }^{\circ} \mathrm{C}\right.$, $\tau=25$ мин, охлаждение на воздухе)

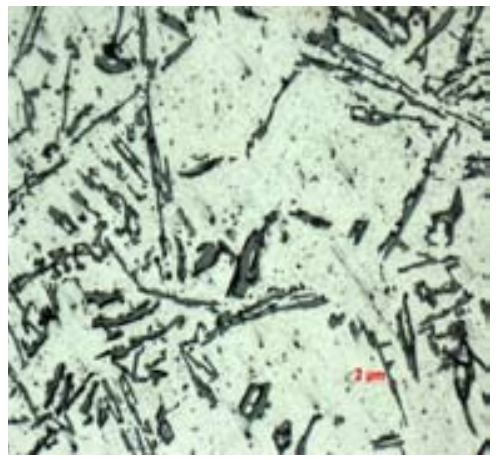

Рис. 15. Микроструктура сплава АК12 в термообработанном состоянии $\left(\mathrm{T}_{3}=585{ }^{\circ} \mathrm{C}\right.$, $\tau=30$ мин, охлаждение на воздухе)

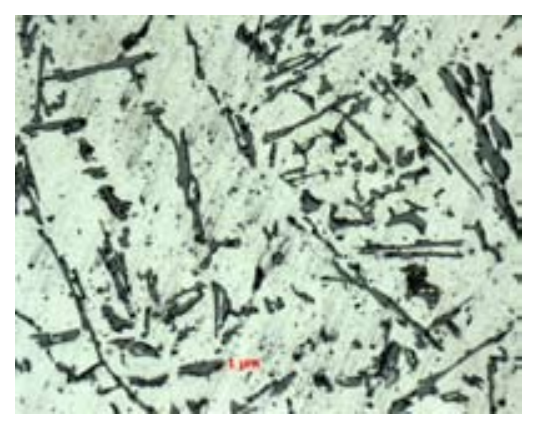

Рис. 16. Микроструктура сплава АК12 в термообработанном состоянии $\left(\mathrm{T}_{3}=585{ }^{\circ} \mathrm{C}, \tau=90\right.$ мин, охлаждение на воздухе)

Роль этого параметра заключается в том, что при использовании разных скоростей охлаждения процессы кристаллизации (взаимодействие сформированных кластеров между собой при образовании зародыша и рост кристаллов) вынуждены протекать за различные промежутки времени.

Рассматривая кластерные взаимодействия как некий особый механизм диффузии, когда в перемещении масс вещества участвуют не отдельные атомы, а целые комплексы кристаллографически связанных между собой групп атомов, эти диффузионные процессы могут проходить с большими скоростями и приводить к резко различным формам образующихся кристаллов в зависимости от внешних условий (температура, время, разница химических потенциалов, концентраций и т.д.).

Использование скорости охлаждения $\sim 10^{4}{ }^{\circ} \mathrm{C} / \mathrm{c}$ обеспечивает выделение кристаллографически не ориентированных кремниевых кристаллов (видимо, нанокристаллов), размер которых может быть соизмерим с размером кластеров в гетерогенном расплаве.

Увеличение длительности кристаллизационных процессов за счет применения охлаждения образцов сплава на воздухе (скорость охлаждения 1-3 град/с) приводит к формированию кристаллов микронных (несколько микронов) размеров. При этом форма кристаллов может быть различной - от компактных кристаллов до пластинчатых (игольчатых), в зависимости от 
степени гетерогенизации расплава с применением времени выдержки в интервале температур кластеризации и гетерогенизации жидкости.

Применение технологической операции охлаждения кластеризованного расплава с печью (скорость охлаждения 0,01-0,03 ${ }^{\circ} \mathrm{C} / \mathrm{c}$ ), т.е. на два порядка меньше, чем охлаждение на воздухе и на 5-6 порядков меньше, чем охлаждение в воде, должно было привести к тому, что формирование зародышей и их кристаллографически ориентированный рост будут происходить путем присоединения диффундирующих кластеров кремния не только в одном преимущественном кристаллографическом направлении, но и в других, менее благоприятных для роста. Поэтому в процессе роста будут формироваться компактные кристаллы кремния, достаточно крупные, имеющие кристаллографическую огранку (рис. 17 - 19).

Нагрев эвтектических сплавов до температуры, на несколько градусов превышающей точку эвтектического равновесия, вызывает расплавление, результатом охлаждения которого становится формирование кластерной смеси. Такая смесь состоит из микрообъемов, характеризующихся наличием ближнего порядка, отвечающего кристаллическому строению фаз, при плавлении которых эти кластеры образовались.

При наличии разницы в строении соответствующих кластерных образований в жидкости происходит перераспределение компонентов, участвующих в образовании таких кластеров,

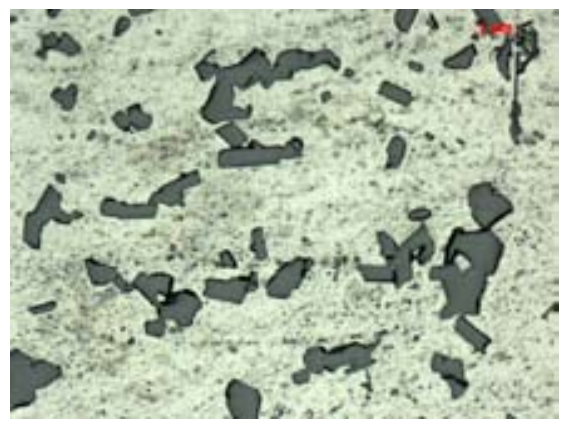

Рис. 17. Микроструктура сплава АК12 в термообработанном состоянии $\left(\mathrm{T}_{3}=578{ }^{\circ} \mathrm{C}\right.$, $\tau=30$ мин, охлаждение с печью до $400{ }^{\circ} \mathrm{C}$, в воду)

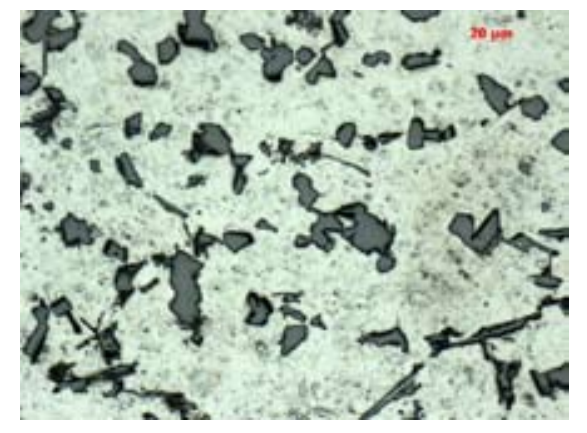

Рис. 18. Микроструктура сплава АК12в термообработанном состоянии $\left(\mathrm{T}_{3}=580{ }^{\circ} \mathrm{C}\right.$, $\tau=15$ мин, охлаждение с печью до $450^{\circ} \mathrm{C}$, в воду)

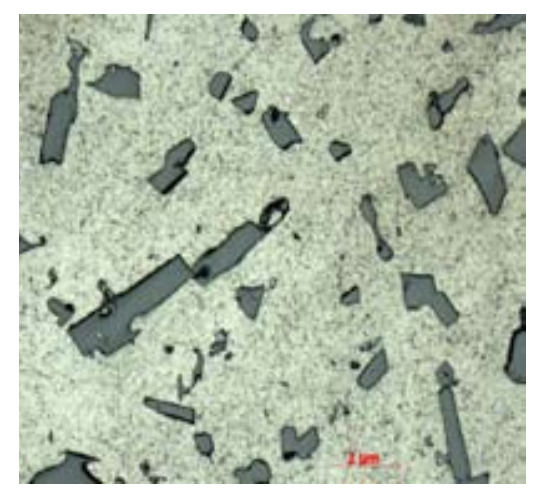

Рис. 19. Микроструктура сплава АК12 в термообработанном состоянии $\left(\mathrm{T}_{3}=585{ }^{\circ} \mathrm{C}, \tau=120\right.$ мин, охлаждение с печью до $430^{\circ} \mathrm{C}$, в воду) 
которые мы фиксируем при резком охлаждении в воде или при более малых скоростях охлаждения (на воздухе, с печью).

\section{Выводы}

Таким образом, в настоящей работе обнаружено явление влияния предкристаллизационных процессов, развивающихся в температурной области на несколько градусов выше начала температур фазового превращения, на формирование конечной структуры сплавов. Сущность обнаруженного явления - предкристаллизационная гетерогенизация исходного металлического раствора в связи с перераспределением компонентов сплава между кластерными образованиями, возникающими в таком растворе до развития фазового превращения. Это явление может найти разнообразные области применения при получении слитков и отливок из сплавов эвтектического типа.

Показано, что степени кластеризации и гетерогенизации расплава зависят от температуры и длительности выдержки в условиях перегрева выше точки эвтектического равновесия, что сказывается на структуре формирующегося при кристаллизации сплава. Установлены условия формирования структуры с компактными выделениями кремниевых кристаллов, которые могут быть рекомендованы при изготовлении изделий различного назначения.

Возможны три различные технологические схемы кластеризационной обработки эвтектических сплавов с различной реализацией.

Наиболее трудно реализуется схема - нагрев до температуры кластеризации расплава с различной длительностью выдержки, с очень быстрым закалочным охлаждением. Недостаток - трудность сохранения формы изделия.

Вторая схема - с использованием ограниченной длительности кластеризации 5-10 мин, с охлаждением на воздухе. Недостаток - возможная нестабильность результатов при изготовлении изделии, опасность сохранения пластинчатых (игольчатых) кристаллов кремния.

Третья схема - с использованием различных длительностей кластеризации, с охлаждением с печью. Недостаток - относительно крупные кремниевые кристаллы. Положительным фактором является возможность применения для сильно заэвтектических сплавов, где новые кристаллы кремния будут соизмеримыми с первичными, но сплавы будут характеризоваться повышенной пластичностью, обусловленной устранением непрерывности эвтектического кремниевого кристалла.

\section{Список литературы}

[1] Пригунова А.Г., Белов Н.А., Таран Ю.Н. Силумины. Атлас микроструктур и фрактограмм промышленных сплавов. М.: МИСиС, 1996. 175 с.

[2] Белов Н.A., Савченко С.В., Хван А В. Фазовый состав и структура силуминов: справочное издание. М.: МИСиС, 2008. 283 с.

[3] Беляев А.И., Романова О.А., Бочвар О.С. и др. Алюминиевые сплавы. Металловедение алюминия и его сплавов: Справочное руководство. М.: Металлургия, 1971. $352 \mathrm{c.}$

[4] Таран Ю.Н., Мазур В.И. Структура эвтектических сплавов. М.: Металлургия, 1978. $312 \mathrm{c}$. 
[5] Золоторевский В.С., Белов Н.А. Металловедение литейных алюминиевых сплавов. М.: МИСиС, 2005. $376 \mathrm{c.}$

[6] Грачев С.В., Бараз В.Р., Богатов А.А., Швейкин В.П. Физическое металловедение: учеб. для вузов. Екатеринбург: УГТУ-УПИ, 2001. 534 с.

[7] Аникина В.И., Жереб В.П., Аникин А.И. и др. Пат. 2525872 РФ (2013) / Б. И. 2014. № 23

[8] Биронт В.С., Блохин И.В., Аникин А.И. // Современные технологии ресурсов. Вып. 8. 